\title{
Fourth Reported Case of Hemoglobin South Florida: A Rare Hemoglobin Variant That Causes Falsely Elevated HbA1c Values
}

\author{
Theresa Ratajczak ${ }^{\mathrm{a}}$, Sadia Afaz ${ }^{\mathrm{b}}$, Ankur Gupta ${ }^{\mathrm{a}, \mathrm{b}, \mathrm{c}}$
}

\begin{abstract}
We report a case of a rare hemoglobin $(\mathrm{Hb})$ variant, $\mathrm{Hb}$ South Florida (Hb-SF) with only three cases reported worldwide to our knowledge since initial description in 1985. It causes falsely elevated glycosylated hemoglobin $(\mathrm{HbAlc})$ results during standard laboratory testing in the range of poorly controlled diabetes mellitus. A 42-year-old woman with a history of sclerosing bone dysplasia was noted to have an elevated $\mathrm{HbAlc}(13.8 \%)$ during routine blood work using the ionexchange high performance liquid chromatography (HPLC) method. The patient did not have a prior diagnosis of diabetes mellitus and denied any symptoms consistent with diabetes. Physical exam was unremarkable. Her blood sugars were normal to minimally elevated. Over several months, she was noted to have persistent elevation in $\mathrm{HbA} 1 \mathrm{c}$ in the range of $12-14 \%$. She remained asymptomatic. The patient was referred to endocrinology clinic. $\mathrm{Hb}$ electrophoresis was performed due to suspicion for a hemoglobinopathy. The patient was noted to be heterozygous for a rare $\mathrm{Hb}$ variant called $\mathrm{Hb}$ South Florida that causes falsely elevated HbA1c levels. Her corrected HbA1c, when evaluated by affinity column HPLC, was in normoglycemic range. $\mathrm{Hb}$ South Florida was first described in 1985 in Tampa Florida and has since been reported in two other cases worldwide. The $\mathrm{Hb}$ is not associated with any clinical disorder reported in literature. There are many commercially available tests for measuring $\mathrm{HbA} 1 \mathrm{c}$ levels. Additionally, structural variants in Hb interfere with many of the methods. Ion-exchange HPLC separates $\mathrm{Hb}$ based on their charge differences. Hb South Florida variant substitutes a neutral amino acid for a charged one, with valine substituted by methionine. This alteration decreases the transit time in the ion exchange column and causes it to co-elute together with $\mathrm{HbA1c}$, giving a falsely elevated value as they get measured as same species. Affinity chromatography is based on affinity of a species for a particular ligand. It recognizes the structure of the N-terminal glycated amino acids of the beta chain of $\mathrm{Hb}$. In the case of $\mathrm{Hb}$ South Florida, it was able to separate the variant $\mathrm{Hb}$ from glycated species. This is the fourth case of $\mathrm{Hb}$ variant South
\end{abstract}

Manuscript accepted for publication April 10, 2015

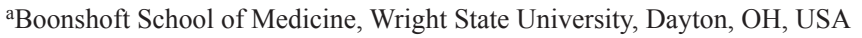
bDepartment of Veteran Affairs, Dayton, OH, USA

${ }^{c}$ Corresponding Author: Ankur Gupta, Boonshoft School of Medicine, Wright State University, Dayton, OH, USA. Email: ankur.gupta@wright.edu

doi: http://dx.doi.org/10.14740/jmc2134w
Florida to our knowledge. It is important for clinicians to keep a wide perspective when making an assessment of diabetes solely based on HbA1c values. Patients who do not present with symptoms consistent with diabetes, and have normal blood glucose should prompt a further workup for abnormal $\mathrm{Hb}$ variants. This should be done in order to prevent incorrect diagnosis and treatment.

Keywords: Hemoglobinopathy; South Florida; Diabetes mellitus

\section{Introduction}

Measurement of glycosylated hemoglobin $(\mathrm{HbAlc})$ is an important test in management of patients with diabetes to assess glycemic control [1]. We report a fourth case of a rare hemoglobin $(\mathrm{Hb})$ variant, $\mathrm{Hb}$ South Florida (Hb-SF) with only three cases reported previously worldwide to our knowledge since its initial description in 1985. It causes falsely elevated HbA1c results during standard laboratory testing in the range of poorly controlled diabetes mellitus [2].

\section{Case Report}

A 42-year-old female with a history of sclerosing bone dysplasia was found to have an elevated $\mathrm{HbA} 1 \mathrm{c}$ of $13.8 \%$ during routine lab work using the ion-exchange high performance liquid chromatography (HPLC) method. Repeat testing showed HbAlc of $12.8 \%$ with fasting blood sugar of $98 \mathrm{mg} /$ dL. Patient did not have a prior diagnosis of diabetes mellitus and denied any symptoms of polyuria, polyphagia, or polydypsia. She denied any family history of diabetes. Physical exam was unremarkable. Routine lab work that included a complete blood count, lipid and renal panel was within normal limits. Her home medication included acetaminophen/ codeine that she takes for bone pain from sclerosing bone dysplasia. She was asked to repeat lab work over a course of several months, which showed persistent elevated $\mathrm{HbA} 1 \mathrm{c}$ in the range of $12-14 \%$ with mildly elevated blood sugar readings (Table 1).

Patient remained asymptomatic. Her random blood glucose readings did not correspond to $\mathrm{HbAlc}$ values. She was referred to the endocrinology clinic for further evaluation. $\mathrm{Hb}$ 
Table 1. HbA1c Results

\begin{tabular}{|llll|}
\hline Date & $\begin{array}{l}\text { HbA1c results done by } \\
\text { ion exchange HPLC }\end{array}$ & $\begin{array}{l}\text { Blood glucose } \\
\text { (mg/dL) }\end{array}$ & $\begin{array}{l}\text { HbA1c done by } \\
\text { affinity column HPLC }\end{array}$ \\
\hline September 13, 2013 & $13.8 \%$ & 98 & \\
\hline September 17, 2013 & $12.7 \%$ & & \\
October 02, 2013 & $12.8 \%$ & 103 & \\
\hline April 05, 2014 & $14.1 \%$ & 109 & $4.2 \%$ \\
\hline April 16, 2014 & $12.7 \%$ & 133 (non-fasting) & \\
\hline
\end{tabular}

electrophoresis was performed due to suspicion for a hemoglobinopathy. The results showed that the patient was heterozygous for a rare $\mathrm{Hb}$ variant called $\mathrm{Hb}$-SF that causes falsely elevated $\mathrm{HbA} 1 \mathrm{c}$ levels [2]. Her corrected HbAlc, when evaluated by affinity column HPLC showed results in the normoglycemic range (Table 2).

\section{Discussion}

Glycosylation is the addition of glucose molecules to amino groups of proteins in a non-enzymatic way [3]. HbA1c is the most abundant fraction of glycosylated hemoglobin, proportional to average blood glucose concentration over the previous 2 - 3 months [1]. The concept of measuring $\mathrm{HbAlc}$ is based on the fact that $\mathrm{Hb}$ formed in new red blood cells enters the circulation with a minimal glucose attached [4]. Red blood cells are freely permeable to glucose and $\mathrm{Hb}$ becomes irreversibly bound with it at a rate dependent on the surrounding blood glucose concentration [4].

Healthy adults $\mathrm{Hb}$ consists of approximately $97 \% \mathrm{HbA}$, $2.5 \% \mathrm{HbA} 2$ and $0.5 \% \mathrm{HbF}$. $\mathrm{Hb} \mathrm{A}$ is composed of four polypeptide chains: two alpha and two beta chains held together by non-covalent bonds [5]. Glycosylation occurs by a nonenzymatic reaction between glucose and $\mathrm{NH} 2$ groups of the $\mathrm{N}$-terminal valine of the beta globin chains [4]. This is a twostep process. First a reversible reaction between the free aldehyde group of glucose and a free animo group on the $\mathrm{Hb}$ molecule forms a Schiff base [6]. This is followed by an irreversible Amadori rearrangement, where the Schiff base is converted to 1-deoxyfructose, producing glycosylated hemoglobin [6].

There are many commercially available tests for meas-

Table 2. Hemoglobin Electrophoresis Results: April 21, 2014

\begin{tabular}{lll}
\hline Hb type & Patient results \% & Normal range \\
\hline $\mathrm{Hb} \mathrm{A}$ & 58.1 & $>95 \%$ \\
$\mathrm{Hb} \mathrm{F}$ & 1 & Ref: none \\
$\mathrm{Hb} \mathrm{S}$ & 0 & Ref: none \\
$\mathrm{Hb} \mathrm{C}$ & 0 & Ref: $\geq 0$ \\
$\mathrm{Hb} \mathrm{A} 2$ & 3.7 & Normal: $0.7-3.1$ \\
Hb variant South Florida* & 37.2 & \\
\hline
\end{tabular}

*Pattern consistent with heterozygous $\mathrm{Hb}$ South Florida. uring $\mathrm{HbAlc}$ levels. Methods of identification are based on either physical, chemical or antibody characteristics [5]. Additionally, structural variants in $\mathrm{Hb}$ interfere with many of these methods [7]. There have been more than $700 \mathrm{Hb}$ variants reported which arise from point mutations in one of the four chains [5]. The current estimation of $\mathrm{Hb}$ variants worldwide is thought to be around $7 \%$ of the population [3].

The four most common types of methods of measuring $\mathrm{HbAlc}$ are affinity column immunoassay, ion-exchange HPLC, boronate affinity HPLC and enzymatic assay [3]. In the affinity column immunoassay method ligands recognize the structure of the N-terminal glycated amino acids of the beta chain. Ion-exchange HPLC separates $\mathrm{Hb}$ based on their charge differences [5]. Boronate method uses acid, which reacts with groups of glucose, bound to $\mathrm{Hb}$. Enzyme-linked method uses an enzyme, which reacts with the $\mathrm{N}$-terminal valine of the $\mathrm{Hb}$ [3].

As mentioned previously, ion-exchange chromatography is a commonly used method to separate $\mathrm{Hb}$ chains, as they elute in the exchange column at different times based on their charge differences [5]. Variant $\mathrm{Hb}$ that elute separately from $\mathrm{HbAlc}$ are not included in this measurement. Abnormal results occur when $\mathrm{a} \mathrm{Hb}$ variant cannot be separated from the $\mathrm{HbAlc}$ fraction [5]. Hb-SF variant substitutes a neutral amino acid for a charged one, with valine substituted by methionine [8]. This alteration decreases its transit time in the exchange column and causes it to co-elute together with $\mathrm{HbAlc}$, giving a falsely elevated value as they get measured as the same species [5].

There are many common hemoglobinopathies such as sickle cell disease, which are known to cause abnormal HbAlc results. These variants can cause either increased or decreased $\mathrm{HbA1c}$ levels, depending on the test type used [7].

$\mathrm{Hb}$-SF was first described in 1985 in Tampa Florida in a 9-year-old boy, referred to the South Florida Diabetes Center. He presented with symptoms of poor weight gain, polyuria, a normal glucose tolerance test, a normal $\mathrm{Hb}$ electrophoresis (cellulose acetate method) and HbAlc of $14.8 \%$ (ionexchange chromatography) [2,9]. Despite the normal electrophoresis results, there was a suspicion for an $\mathrm{Hb}$ variant due to elevated $\mathrm{HbA}$ lc levels in the absence of diabetes. The authors found that the ion-exchange chromatography results were not consistent when repeated with affinity column immunoassay testing. The latter was able to correctly report the patients $\mathrm{HbAlc}$, without the false values caused by the nonglycosylated hemoglobin. They concluded that when this $\mathrm{Hb}$ variant is suspected the test should be repeated with affinity 
column testing $[2,9]$. The variant $\mathrm{Hb}$-SF has since been reported in two other cases worldwide, one case in Turkey in 2013 [10] and one in Malaysia in 2006 [11]. The variant $\mathrm{Hb}$ is not associated with any clinical disorder reported in literature [9].

In the case of our patient, she initially underwent $\mathrm{HbAlc}$ testing with ion-exchange chromatography that showed elevated levels. This was subsequently repeated with affinity chromatography, which showed normoglycemic results analogous to the original case from Florida.

\section{Conclusion}

This is the fourth case of Hb-SF to our knowledge. It is important for clinicians to keep a wide perspective when making an assessment of diabetes solely based on $\mathrm{HbA} 1 \mathrm{c}$ values. Patients who do not present with symptoms consistent with diabetes, and have normal blood glucose should prompt a further workup for abnormal $\mathrm{Hb}$ variants. This should be done in order to prevent incorrect diagnosis and treatment. It is also important to remember that there are many $\mathrm{Hb}$ variants in the populations, some of which are clinically silent but interfere with routine laboratory tests.

\section{Acknowledgement}

We would like to also acknowledge the assistance of Dr Ronald J. Markert, Ph.D., Vice Chairman for Research, Department of Internal Medicine, Wright State University Boonshoft School of Medicine, Dayton Ohio, for his comments and critical review of the manuscript.

\section{Conflict of Interest}

The authors of this article have no conflict of interest to declare.

\section{References}

1. ADA guidelines. http://www.diabetes.org/living-withdiabetes/treatment-and-care/blood-glucose-control/a1c/.

2. Shah SC, Malone JI, Boissel JP, Kasper TJ. Hemoglobin South Florida. New variant with normal electrophoretic pattern mistaken for glycosylated hemoglobin. Diabetes. 1986;35(10):1073-1076.

3. Little RR, Roberts WL. A review of variant hemoglobins interfering with hemoglobin A1c measurement. J Diabetes Sci Technol. 2009;3(3):446-451.

4. Denise RF. Biochemistry (Lippincott Illustrated Reviews Series) May 24, 2013. LWW; Sixth, North American Edition edition.

5. Bry L, Chen PC, Sacks DB. Effects of hemoglobin variants and chemically modified derivatives on assays for glycohemoglobin. Clin Chem. 2001;47(2):153-163.

6. Horace SI, Harriet L. Mutarotation, Hydrolysis, and Rearrangement Reactions of Glycosylamines. Frush J Org Chem. 1958;23(9):1309-1319.

7. Behan KJ, Merschen J. HbA1c does not always estimate average glucose. Clin Lab Sci. 2011;24(2):71-77.

8. Boissel JP, Kasper TJ, Shah SC, Malone JI, Bunn HF. Amino-terminal processing of proteins: hemoglobin South Florida, a variant with retention of initiator methionine and $\mathrm{N}$ alpha-acetylation. Proc Natl Acad Sci U S A. 1985;82(24):8448-8452.

9. Malone JI, Shah SC, Barness LA. Hemoglobin South Florida: a genetic variant with laboratory recognition of only $20 \%$ of its product. Am J Med Genet Suppl. 1987;3:227-231.

10. Aslanger AD, Akbulut A, Tokgoz G, Turkmen S, Yararbas K. First Observation of Hb South Florida [beta 1(NA1) Val $>$ Met] in Turkey. Turk J Haematol. 2013;30(2):223224.

11. Tan JA, Chin PS, Wong YC, Tan KL, Chan LL, George E. Characterisation and confirmation of rare beta-thalassaemia mutations in the Malay, Chinese and Indian ethnic groups in Malaysia. Pathology. 2006;38(5):437-441. 